\title{
Study of an alkali-activated binder based on tungsten mining mud and brick powder waste
}

\author{
Naim Sedira ${ }^{1}$, and João Castro-Gomes ${ }^{1,}$ \\ ${ }^{1}$ Centre of Materials and Building Technologies (C-MADE/UBI), Department of Civil Engineering \\ and Architecture, University of Beira Interior (UBI), 6201-001 Covilhã, Portugal
}

\begin{abstract}
Blends of Tungsten mining waste mud (TMWM) and brick waste powder (BP) with different dosages were used as precursors for the study of a new binder obtained by alkali-activation. The synthesis was obtained at $60^{\circ} \mathrm{C}$ curing during the first 24 hours and at $20^{\circ} \mathrm{C}$ during the remaining period. A combination of sodium hydroxide $(\mathrm{SH})$ and sodium silicate (SS) solutions was used with $\mathrm{SS} / \mathrm{SH}$ weight ratio equal 1.5. The solid precursors/liquid activators weight ratio equal to 4 . And the modules $\mathrm{SiO}_{2} / \mathrm{Na}_{2} \mathrm{O}$ increase with the increasing of BP dosages 5.21 and 5.59 for dosages $10 \%$ and $50 \%$, respectively. Mineralogical characterisation of raw materials was carried out by X-ray diffraction (XRD). The effect of the dosage of BP on the compressive strength and pore size distribution of the new binder was investigated from 24 hours up to 28 days. The pore size distribution was obtained mercury intrusion porosimetry (MIP). The increase in the dosages of BP, between 10 to $50 \%$, was followed by an increase in compressive strength, from 25 to $59 \mathrm{MPa}$, for all the tested ages. The binder matrix become more dense and compact with the gradually increase of BP dosages, as found out by MIP.
\end{abstract}

\section{Introduction}

The cement manufacturing process is responsible for about $6 \%$ of the global $\mathrm{CO}_{2}$ emissions. The increase in carbon dioxide $\left(\mathrm{CO}_{2}\right)$, greenhouse gases and the disposal problems of industrial waste caused serious impact on the environment and climate changes. The alkaliactivated binders technology offers other feasible cementing materials that could reduce the cement industries $\mathrm{CO}_{2}$ emissions by about $80 \%$ to $90 \%$ [1], [2]. Mining and/or construction and demolition activities accounted for 3.0 tonnes out of a total of 3.2 tonnes per inhabitant of mineral waste, equivalent to $93.5 \%$ of the total mineral waste generated across EU. The construction waste generated $45 \%$ of total waste and its production is growing at a rapid pace [3]. The increase in the amount of industrial wastes such as waste glass, plastics and fired clays cause serious environmental problems [4], [5].

In Europe, the activities of mining and quarrying generate approximately $55 \%$ of total industrial wastes according to Eurostat [3]. Thus, the waste generated from mining and quarry industry accumulated in large deposits present a potential risk. The storage of these

\footnotetext{
*Corresponding author: castro.gomes@ubi.pt
} 
wastes directly on land may lead to various environmental issues [6]. Different mine tailings have been used in various previous studies as precursors for alkali-activation [7]. Tungsten tailing is the waste generated from a tungsten mine. It can lead to environmental risk, like contamination of soil, pollution of water and air in the surrounding areas [8]. According to Castro-Gomes et al. [6], the mineralogy of tailings from Panasqueira tungsten mining waste was found to be mainly quartz and muscovite. However tungsten mining waste can be re-used in several innovative applications [9]. Recently, Sedira and CastroGomes [10] obtained an alkali-activated binder where $50 \%$ of the tungsten mining waste was replaced by electronic arc furnace slag (EAFS) to increase the overall amorphous $\mathrm{SiO}_{2}$ and calcium content. The compressive strength of alkali-activated binder was above 30 MPa after 90 days curing.

Brick waste powder (BP) is one of the different types of ceramic waste used to develop alkali-activated binders [11]. Several studies and research were made to develop either alkali-activated materials or hybrid cement using BP as a source of alumina silicate materials and other minerals. Early studies focused on producing alkali-activated materials based on itself or on the combination of BP with and other minerals; namely, different ceramic waste types [12], [13], BP with concrete waste [14] and BP with GGBFS [15], brick waste powder with fly ash [16], red clay brick waste only [17], [18] and ordinary Portland cement with BP [18].

In the present study, we evaluated the synthesis of an alkali-activated binder (AAB) obtained by blending Tungsten mine waste mud (TMW) and brick powder (BP), using as activators a mix solution of sodium silicate (SS) and sodium hydroxide (SH). This research work is part of REMINE research program (H2020 RISE-Marie Curie Action) that aims to develop new ideas for the reuse of mining wastes into innovative alkali-activated-based materials for structures and buildings.

\section{Experimental}

\subsection{Material}

The materials used in this work are Tungsten mining waste mud (TMWM) and brick waste powder (BP). The mud waste was collected from Panasqueira mine located in Covilhã, Portugal. The mud was dried in oven at $60^{\circ} \mathrm{C}$ temperature for 24 hours. Afterwards the dried mud was mechanically disaggregated using a crushing machine and sieved under 500 $\mu \mathrm{m}$ particle size.

Regarding BP the following processing procedures were adopted: First, brick coarse waste was submitted to washing to remove contaminations and to separate the other construction impurities; Afterwards it was placed in the oven at a temperature of $60^{\circ} \mathrm{C}$, for 24 hours for complete drying; Finally, the coarse brick waste was crushed using a crushing device and was sieved to obtain particles with size under $250 \mu \mathrm{m}$.

The chemical compositions of these materials, were determined by scanning electron microscopy (SEM-EDX, HITACHI S-3400N).

The bulk powder densities of TMWM and BP were determined using a gas displacement pycnometer (model AccuPyc 1340, Micromeritics, Norcross, Georgia) and were determined as 3.03 and $2.73 \mathrm{~g} / \mathrm{cm}^{3}$, respectively. The Blaine fineness of the different powders was determined according to EN 196-6, by using a Blaine air permeability apparatus (model ACMEL BSA1) and were determined as 3339 and $2954 \mathrm{~cm}^{2} / \mathrm{g}$, respectively. Loss on ignition (LOI) was obtained by TGA analysis by using TA Instrument SDT Q 50, TMWM loss about $11.6 \%$ of weight and BP loss about $3.6 \%$ of weight at the 
temperature $1000{ }^{\circ} \mathrm{C}$. The physical characteristics and chemical compositions of the TMWM and BP materials are presented in Table 1.

Table 1. Physical characteristics and chemical composition (\% mass) of waste materials.

\begin{tabular}{|c|c|c|}
\hline \multirow{2}{*}{ Composition/Properties } & \multicolumn{2}{|c|}{ Materials } \\
\hline & BP & TMWM \\
\hline $\mathrm{O}$ & 47.32 & 38.26 \\
\hline $\mathrm{Si}$ & 27.39 & 18.2 \\
\hline $\mathrm{Al}$ & 13.09 & 7.51 \\
\hline $\mathrm{Ti}$ & 0.61 & 0.3 \\
\hline $\mathrm{S}$ & 0.15 & 2.64 \\
\hline $\mathrm{K}$ & 2.40 & 3.39 \\
\hline $\mathrm{Ca}$ & 0.57 & 0.41 \\
\hline $\mathrm{Fe}$ & 5.52 & 9.02 \\
\hline $\mathrm{Mg}$ & 0.87 & 2.43 \\
\hline $\mathrm{Na}$ & 0.37 & 0.80 \\
\hline $\mathrm{P}$ & 0.06 & - \\
\hline $\mathrm{Zn}$ & - & 1.09 \\
\hline Other & 1.66 & 15.89 \\
\hline LOI* & 3.8 & 11.6 \\
\hline Density $\mathrm{g} / \mathrm{cm}^{3}$ & 2.7339 & 3.0319 \\
\hline Blaine specific area $\mathrm{cm}^{2} / \mathrm{g}$ & 2954 & 3339 \\
\hline$*$ LOI, Loss on ign & at 1000 & \\
\hline
\end{tabular}

For the alkaline activators, the sodium hydroxide solution was prepared by dissolving sodium hydroxide pellets $(98 \%$ purity, obtained from Fisher Scientific, Schwerte, Germany) in deionized water and allowed to cool before use. Sodium silicate (obtained from Solvay SA, Póvoa de Santa Iria, Portugal) presented the following chemical composition: $\mathrm{SiO}_{3} / \mathrm{Na}_{2} \mathrm{O}=3.23$ (8.60\% by weight $\mathrm{Na}_{2} \mathrm{O}, 27.79 \%$ by weight $\mathrm{SiO}_{2}, 63.19 \%$ by weight $\mathrm{H}_{2} \mathrm{O}$, and $0.4 \%$ by weight $\mathrm{Al}_{2} \mathrm{O}_{3}$ ).

-a) TMWM

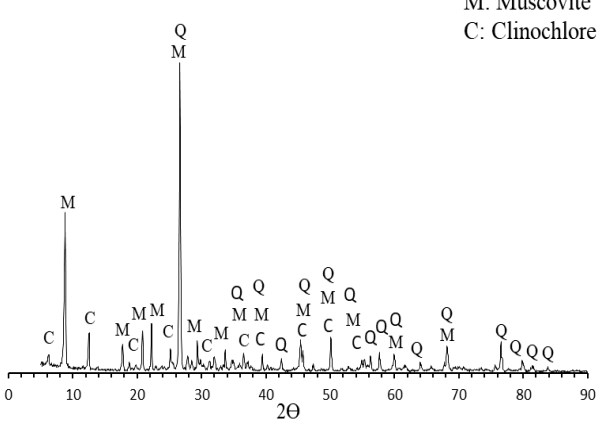

-b) BP

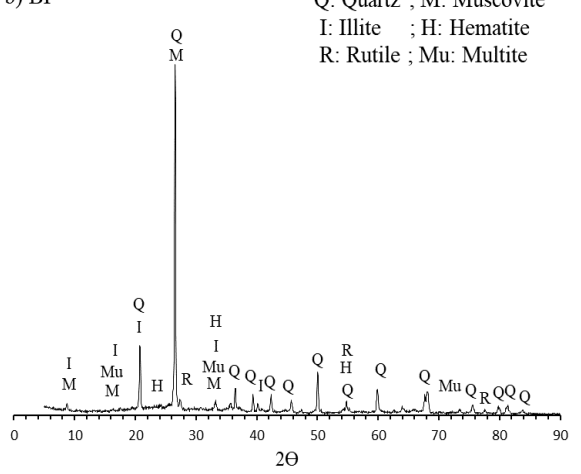

Fig. 1. X-ray diffractograms of TMWM and BP - phases identified are Quartz (Q), Muscovite (M), Clinochlore (C), Hematite (H), Illite (I), Rutile (R), Mulite (Mu).

TMWM and BP X-ray diffractograms are presented in figure 1. The X-ray diffractogram of the TMWM indicates it has a crystalline nature and is consists mainly of muscovite and quartz, which were identified by their characteristic, as follows: muscovite (Ref. PDF\#46-1409), quartz (Ref. PDF\#46-1045) and clinochlore (Ref. PDF\#29-0701) as 
shown in figure 1-a) [19]. X-ray diffractogram spectra of BP, as presented in figure 1-b) indicates the semi-crystalline degree of the waste material and the presence of quartz $\mathrm{SiO}_{2}$ (Ref. PDF\#46-1045) as the main phase.

\subsection{Synthesis and analysis}

The binder mixes were produced by mixing of TMWM and BP as solid precursors, with sodium silicate and sodium hydroxide as alkaline activator solutions. A solid precursors/activator solutions weight ratio of 4 was used, the volume ratio between the two waste materials and the modules $\mathrm{SiO}_{2} / \mathrm{Na}_{2} \mathrm{O}, \mathrm{SiO}_{2} / \mathrm{Al}_{2} \mathrm{O}_{3}$ weight ratio are shown in the Table 2 .

Table 2. Mixes compositions.

\begin{tabular}{|c|c|c|c|}
\hline $\begin{array}{l}\text { Specimen } \\
\text { labels }\end{array}$ & $\begin{array}{l}\text { Volume proportions for the } \\
\text { blended waste materials }\end{array}$ & Variables & Ratios \\
\hline \multirow{3}{*}{$\mathrm{H} 1$} & \multirow{3}{*}{$10 \% \mathrm{BP}$ and $90 \% \mathrm{TMWM}$} & $\mathrm{SiO}_{2} / \mathrm{Na}_{2} \mathrm{O}$ & 5.21 \\
\hline & & $\mathrm{SiO}_{2} / \mathrm{Al}_{2} \mathrm{O}_{3}$ & 7.1 \\
\hline & & Precursor/Activator ratio (P/A) & 4 \\
\hline \multirow{3}{*}{$\mathrm{H} 2$} & \multirow{3}{*}{$20 \% \mathrm{BP}$ and $80 \%$ TMWM } & $\mathrm{SiO}_{2} / \mathrm{Na}_{2} \mathrm{O}$ & 5.29 \\
\hline & & $\mathrm{SiO}_{2} / \mathrm{Al}_{2} \mathrm{O}_{3}$ & 6.9 \\
\hline & & Precursor/Activator ratio (P/A) & 4 \\
\hline \multirow{3}{*}{$\mathrm{H} 3$} & \multirow{3}{*}{$30 \% \mathrm{BP}$ and $70 \%$ TMWM } & $\mathrm{SiO}_{2} / \mathrm{Na}_{2} \mathrm{O}$ & 5.38 \\
\hline & & $\mathrm{SiO}_{2} / \mathrm{Al}_{2} \mathrm{O}_{3}$ & 6.75 \\
\hline & & Precursor/Activator ratio (P/A) & 4 \\
\hline \multirow{3}{*}{$\mathrm{H} 4$} & \multirow{3}{*}{$40 \% \mathrm{BP}$ and $60 \%$ TMWM } & $\mathrm{SiO}_{2} / \mathrm{Na}_{2} \mathrm{O}$ & 5.49 \\
\hline & & $\mathrm{SiO}_{2} / \mathrm{Al}_{2} \mathrm{O}_{3}$ & 6.58 \\
\hline & & Precursor/Activator ratio (P/A) & 4 \\
\hline \multirow{3}{*}{ H5 } & \multirow{3}{*}{$50 \% \mathrm{BP}$ and $50 \%$ TMWM } & $\mathrm{SiO}_{2} / \mathrm{Na}_{2} \mathrm{O}$ & 5.59 \\
\hline & & $\mathrm{SiO}_{2} / \mathrm{Al}_{2} \mathrm{O}_{3}$ & 6.4 \\
\hline & & Precursor/Activator ratio (P/A) & 4 \\
\hline
\end{tabular}

The blended mixtures were activated with a combination of the following solutions: $67 \%$ of Sodium Silicate (SS) $-\mathrm{Na}_{2} \mathrm{SiO}_{3}$ and $33 \%$ of $10 \mathrm{M}$ of Sodium Hydroxide (SH) $\mathrm{NaOH}$. Before beginning to prepare the mixtures, both SS and SH activators, with a mass ratio of 3:2 were mixed together. Afterwards, the liquid activators solution was mixed the precursors and poured in the curing moulds. Then, the filled moulds were placed in an oven at a temperature of $60^{\circ} \mathrm{C}$ for 24 hours, for synthesis. To avoid water evaporation the TMWM-BP alkali-activated binders, the filled moulds were wrapped with plastic film during the synthesis to avoid water evaporation. After the initial 24 hours curing period, the specimens were demoulded and were left to cure in laboratory conditions (about $20{ }^{\circ} \mathrm{C}$ ) for $3,7,14$ and 28 days.

The compressive strength tests were performed using a $3000 \mathrm{kN}$ electro-hydraulic mechanical testing machine (ADR Touch 3000 BS EN Compression Machine with Digital Readout and Self Centring Platen), in accordance with EN 196-1. Compressive strength data was obtained using $25 \mathrm{~mm}$ cubic size specimens.

Mercury intrusion porosimetry (MIP) was adopted to study the pore structure of BPTMWM alkali-activated binders. Using Microporometrics AutoPore IV 9500 V1.07. Mercury porosimetry data is obtained by recording the volume of mercury that penetrates the porous specimen as a function of pressure. MIP measurement was applied to determine the pore structure difference i.e., difference in porosity and pore size distribution. 


\section{Results and discussion}

\subsection{Compressive strength}

The compressive strength results of TMWM-BP alkali-activated binders (average of testing 5 specimens per each mixture) were obtained at the ages of 1,3,7, 14 and 28 days. Figure 2 shows the development of compressive strength in terms of the dosage of BP used in the TMWM-BP alkali-activated binders. Mixture H1 reached $10 \mathrm{MPa}$ compressive strength after the first day curing. It was the lowest value obtained regarding all mixes tested. At 28 days, the compressive strength obtained for the same mix (H1) was $25 \mathrm{MPa}$. Thus, after one day curing the compressive strength represented about $40 \%$ of 28 days compressive strength. Mixture H5 obtained a compressive strength of $22.4 \mathrm{MPa}$, after one day curing, being the highest result corresponding to the highest BP (50\%) content. This initial result represents $32,6 \%$ of the 28 days curing $\mathrm{H} 5$ compressive strength, that was about $59 \mathrm{MPa}$, and the highest result of all mixtures. The increase of BP dosage the increase in compressive strength from $25 \mathrm{MPa}$ after one day curing to $59 \mathrm{MPa}$ after 28 days curing, corresponding to $\mathrm{H} 1$ and $\mathrm{H} 5$ samples, respectively. The increase of BP content from 10 to $50 \%$ resulted of a $136 \%$ compressive strength increase. Significant development in compressive strength was observed from the first day up to 14 days of curing. In comparison to the 28 days maximum compressive strength, the compressive strength relative increase from the first up to 14 days ranges between $95 \%$ and $99 \%$ for all mixtures. Generally, the higher the dosage of BP in the mixes, the higher the compressive strength obtained in all the tested ages [20].

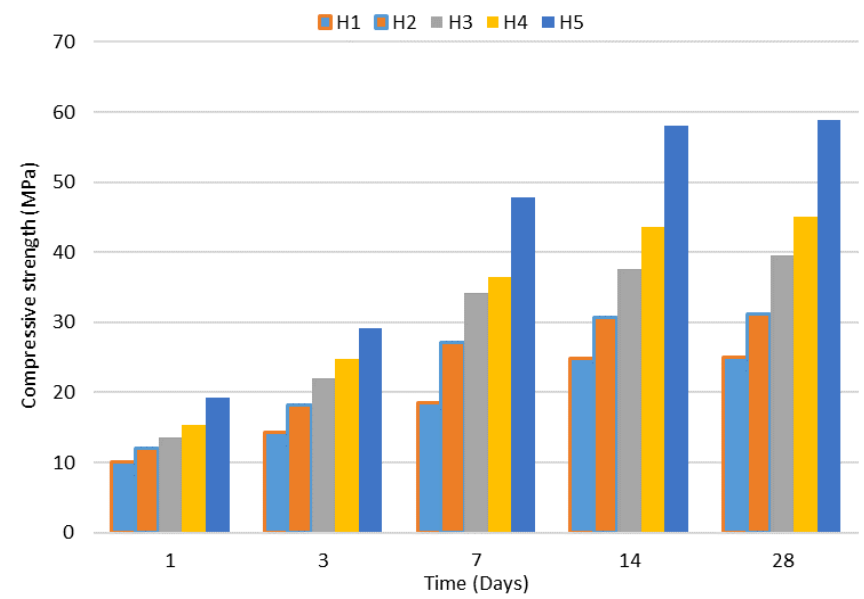

Fig. 2. Development in the compressive strength of alkali-activated mixtures (H1 to H5) containing $10,20,30,40$ and $50 \%$ of $\mathrm{BP}$, as a function of time.

\subsection{Pore size distribution}

MIP analysis revealed that the higher dosage of BP the higher percentages of pores with smaller diameter $(<20 \mathrm{~nm}$ and diameter between 20 and $50 \mathrm{~nm})$, namely in the samples $\mathrm{H} 3$, $\mathrm{H} 4$ and $\mathrm{H} 5$. The samples $\mathrm{H} 1, \mathrm{H} 2$ presented the lesser percentages of smaller pores $(<20 \mathrm{~nm}$ and diameter between 20 and $50 \mathrm{~nm}$ ) and higher percentages of larger pores size ( $50 \mathrm{~nm}$ to up to $800 \mathrm{~nm}$ ), as show in figure 3 . Thus, it was verified that with increasing BP content in 
the mixes the hardened paste becomes denser, since with higher BP dosages more quantity of alkali-activated gel is formed that can fill in the micro pores in TMWM-BP hardened binder, leading to further increase in the density of final matrix phase [21]. The changes in pore size distribution for different $\mathrm{H}$ mixes can explain the increase in the compressive strength for higher dosages of $\mathrm{BP}$, and along time of reaction.

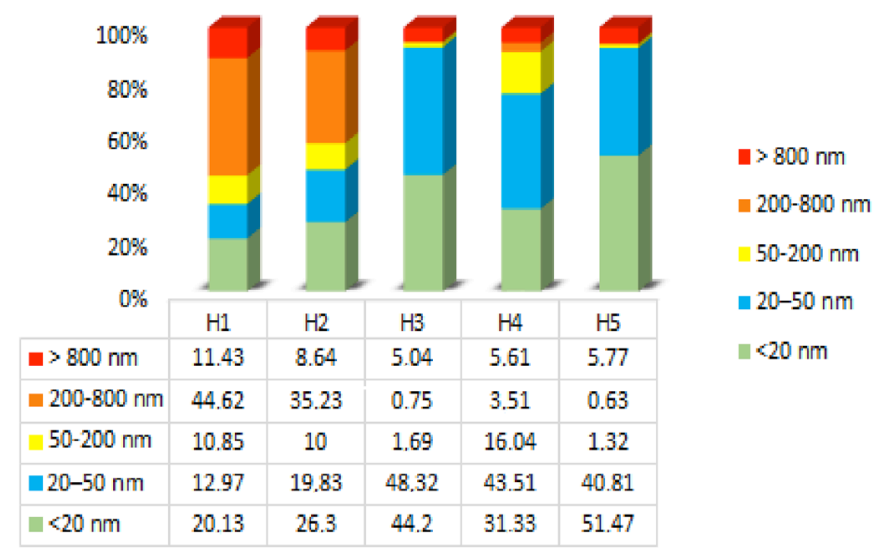

Fig. 3. Pore size distribution (\%) of different alkali-activated binder samples.

The pore size distribution and the critical pore size was determined for different BP dosages. As well, known the pore width corresponding to the highest rate of mercury intrusion per change in pressure is known as the "threshold," "critical," or "percolation" pore width. After achieving this highest rate of intrusion, mercury can penetrate the interior of the sample [22]. The relationships between critical pore size and the dosages of BP contained in the five samples are presented in Figure 4. The differential distribution curves for the samples H1, H2 and $\mathrm{H} 3$ have several peak shifts. While, for the samples $\mathrm{H} 4$ and $\mathrm{H} 5$ only one rounded peak dominates the differential distribution curves. The initial peak corresponding to lower pore size may correspond to the intrusion of mercury through a connected capillary network, while the rounded peak may correspond to the crushing of interposed reaction products, as found by other authors [23].

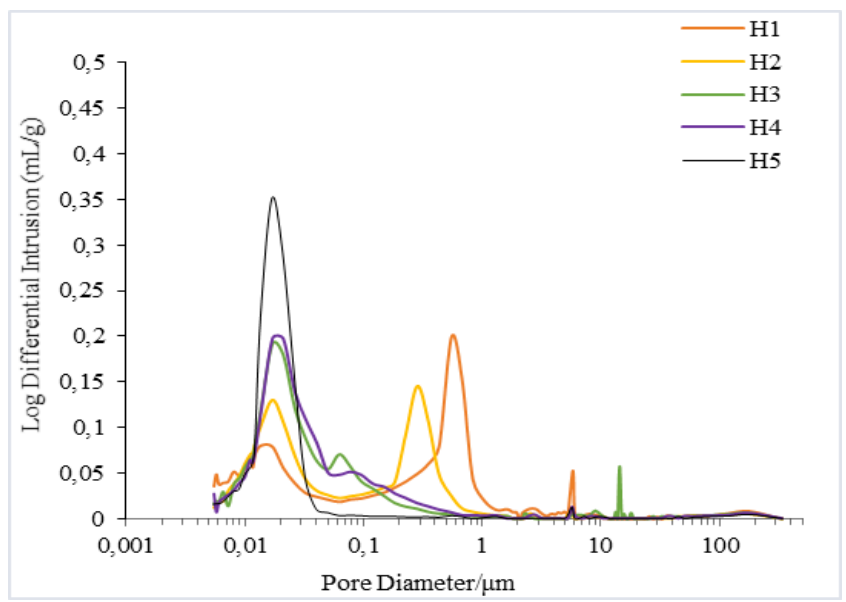

Fig. 4. Overlay of the differential distribution curve for the specimens cured for 28 days. 


\section{Conclusions}

In this study the synthesis of an alkali-activated binder (AAB) obtained by blending Tungsten mine waste mud (TMW) and brick powder (BP), using as activators a mix solution of sodium silicate (SS) and sodium hydroxide ( $\mathrm{SH}$ ), was demonstrated. It was demonstrated that brick waste powder has a positive effect on the mechanical properties of alkali-activated binders when blended with other mineral wastes, such as Tungsten mining waste mud.

The blend of 50\% of brick waste powder and 50\% of TMWM resulted in an alkaliactivated material with high compressive strength and dense structure.

This research was partially supported by European Commission under Horizon 2020, Marie Skłodowska-Curie Actions, Research and Innovation Staff Exchange (RISE), by REMINE - "Reuse of Mining Waste into Innovative Geopolymeric-based Structural Panels, Precast, Ready Mixes and Insitu Applications". Project no 645696. (https://reminemsca.wordpress.com). This work was also partially financed by Portuguese national funds through FCT - Foundation for Science and Technology, IP, within the research unit C-MADE, Centre of Materials and Building Technologies (CIVE-Central covilhã-4082), University of Beira Interior, Portugal.

\section{References}

1. S. Usha, D.G. Nair, S. Vishnudas, Int. J. Civ. Eng. Technol. 5, 219-225 (2014)

2. J. Davidovits, World Resour. Rev. 6, 263-278 (1994)

3. Waste statistics Main statistical findings -Total waste generation (Eurostat ,2016).

4. V. Loryuenyong, T. Panyachai, K. Kaewsimork, C. Siritai, Waste Manag. 29, 2717$2721(2009)$

5. P. P. Peña et al., Adv. Mater. Sci. Eng. 2016, 2842969 (2016)

6. J. P. Castro-Gomes, A. P. Silva, R. P. Cano, J. Durán Suarez, A. Albuquerque, J. Clean. Prod. 25, 34-41 (2012)

7. N. Sedira, J. Castro-Gomes, G. Kastiukas, X. Zhou, A. Vargas, Min. Sci. 24, 29-58 (2017)

8. B. Wilson, F.B. Pyatt, Sci. Total Environ. 370, 401-408 (2006)

9. J. Castro-Gomes et al., International Congress on Engineering UBI, (Portugal, 2017)

10. N. Sedira, J. Castro-gomes, REMINE - International Conference \& Brokerage Event (RICON17) - UBI (Portugal, 2017)

11. L. Reig, M.M. Tashima, L. Soriano, M.V. Borrachero, J. Monzó, J. Payá, Waste and Biomass Valorization 4, 729-736 (2013)

12. F. Puertas, A. Barba, M.F. Gazulla, M.P. Gómez, M. Palacios, Mater. Construcción 56, 73-84 (2006)

13. Z. Sun et al., Constr. Build. Mater. 49, 281-287 (2013)

14. A. Allahverdi, E.N. Kani, Int. J. Civ. Eng. 7, 154-160 (2009)

15. N.R. Rakhimova, R.Z. Rakhimov, Mater. Des. 85, 324-331 (2015)

16. P. Rovnanik, B. Reznik, P. Rovnanikovà, Procedia Eng. 151, 108-113 (2016).

17. K. Komnitsas, D. Zaharaki, A. Vlachou, G. Bartzas, M. Galetakis, Adv. Powder Technol. 26, 368-376 (2015)

18. R. A. Robayo, A. Mulford, J. Munera, R. Mejia de Gutiérrez, Constr. Build. Mater., 128, 163-169 (2016) 
19. F. Pacheco-Torgal, J. Castro-Gomes, S. Jalali, Constr. Build. Mater. 23, 200-209, (2009)

20. N. Sedira, J. Castro-Gomes, M. Magrinho, Constr. Build. Mater. (to be published) (2018)

21. X. Guo, H. Shi, X. Wei, Cem. Concr. Compos. 79, 53-61 (2017)

22. D.N. Winslow, S. Diamond, ASTM J. Mater. 5, 564-585 (1969)

23. R.A. Cook, K.C. Hover, Cem. Concr. Res. 29, 933-943 (1999) 